\title{
Elastic curvature constants of lipid monolayers and bilayers
}

\author{
Derek Marsh* \\ Max-Planck-Institut für biophysikalische Chemie, Dept. Spektroskopie, 37070 Göttingen, Germany
}

Received 23 June 2006; received in revised form 22 August 2006; accepted 29 August 2006

Available online 6 September 2006

\begin{abstract}
Bending elasticity is an important property of lipid vesicles, non-lamellar lipid phases and biological membranes. Experimental values of the mean curvature moduli, $k_{\mathrm{c}}$, of lipid bilayers and of the monolayer leaflets of inverted hexagonal $\left(\mathrm{H}_{\mathrm{II}}\right)$ phases of lipids are tabulated here for easy reference. Experimental estimates of the Gaussian curvature modulus, $\bar{k}_{\mathrm{c}}$, are also included. Consideration is given to the relation between the bending moduli of bilayers and the constituent monolayer leaflets. Useful mathematical relations involving the bending moduli and spontaneous curvature are summarized.
\end{abstract}

(C) 2006 Elsevier Ireland Ltd. All rights reserved.

Keywords: Lipid bilayer; Elasticity; Curvature modulus; Bending rigidity; Gaussian curvature; Spontaneous curvature

\section{Introduction}

The elastic bending constants of lipid assemblies determine a variety of membrane-associated physical and functional properties (see, e.g., Evans and Skalak, 1980; Cevc and Marsh, 1987). They can control membrane vesicle shape (Deuling and Helfrich, 1976; Lipowsky, 1991), affect the structure and formation of interlamellar attachments and non-lamellar lipid phases (Siegel, 1999; Templer et al., 1995), and may also play an important role in membrane fusion processes (Chernomordik and Kozlov, 2003). In addition, the elastic moduli determine the scale of ther-

Abbreviations: PtdEtn, phosphatidylethnolamine; PtdCho, phosphatidylcholine; PtdSer, phosphatidylserine; Gro, glycerol; Gal, galactosyl; $\mathrm{C}(12: 0)$, lauroyl; $\mathrm{C}(14: 0)$, myristoyl; $\mathrm{C}(16: 0)$, palmitoyl; $\mathrm{C}(18: 0)$, stearoyl; $\mathrm{C}\left(18: 1 \mathrm{c} \Delta^{9}\right)$, oleoyl; $\mathrm{C}\left(18: 1 \mathrm{c} \Delta^{6}\right)$, petroselinoyl; $\mathrm{C}\left(18: 1 \mathrm{t} \Delta^{9}\right)$, elaidoyl; $\mathrm{C}\left(18: 2 \mathrm{c} \Delta^{9,12}\right)$, linoleoyl; $\mathrm{C}\left(18: 3 \mathrm{c} \Delta^{9,12,15}\right)$, linolenoyl; $\mathrm{C}\left(20: 4 \mathrm{c} \Delta^{5,8,11,14}\right)$, arachidonyl; $\mathrm{C}\left(22: 1 \mathrm{c} \Delta^{13}\right)$, erucoyl; Phy, phytanoyl

* Tel.: +49 551201 1285; fax: +495512011501.

E-mail address: dmarsh@gwdg.de. mally induced elastic bending fluctuations (Helfrich, 1978), which modulate membrane-membrane interactions (Evans and Parsegian, 1986), and also rescale the lateral compressibility (Evans and Rawicz, 1990) in a way that might have functional consequences, e.g., for membrane insertion of proteins (Marsh et al., 2006). On the functional side, together with the spontaneous or intrinsic curvature (Gruner, 1985), the elastic constants can modulate or even control the activity of membraneassociated enzymes (Attard et al., 2000) and ion channels (Keller et al., 1993; Perozo et al., 2002). From a theoretical point of view, the elastic bending constants are related directly to the lateral pressure (or stress) profile across the lipid bilayer or monolayer (Helfrich, 1981; Szleifer et al., 1990), which can be related to the lipid structure (Marsh, 1996a).

The starting point for any discussion of bending elastic constants is the Helfrich expression for the free energy of bending for a membrane (or monolayer) surface of area $A$ (Helfrich, 1973):

$\Delta G_{\mathrm{c}}\left(\bar{c}, \bar{c}_{\mathrm{G}}\right)=\frac{1}{2} k_{\mathrm{c}} A\left(\bar{c}-c_{\mathrm{o}}\right)^{2}+\bar{k}_{\mathrm{c}} A \bar{c}_{\mathrm{G}}^{2}$ 


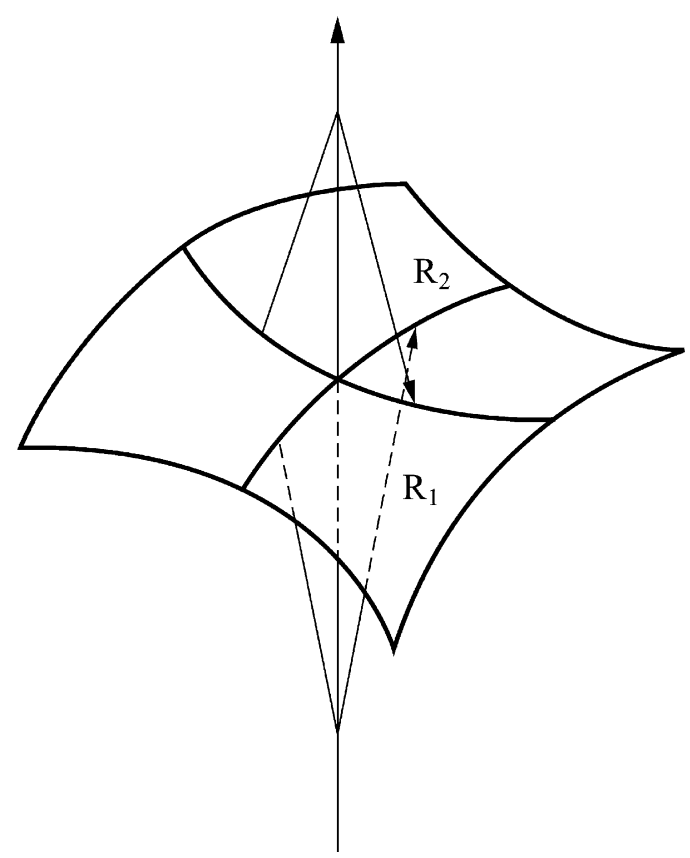

Fig. 1. Bending of a lipid monolayer with principal curvatures $c_{1}=1 / R_{1}$ and $c_{2}=1 / R_{2}$. The mean curvature is given by $\bar{c}=c_{1}+c_{2}$ and the Gaussian curvature is given by $\bar{c}_{\mathrm{G}}^{2}=c_{1} c_{2}$. For cylindrical bending, $\bar{c}=c_{1}$ and $\bar{c}_{\mathrm{G}}=0$, for a spherical vesicle $/$ micelle, $\bar{c} / 2=c_{1}=$ $c_{2}=\bar{c}_{\mathrm{G}}$, and for a saddle-splay surface, $\bar{c}=0$, i.e., $c_{1}=-c_{2}$.

where the mean (or total) curvature is $\bar{c}=c_{1}+c_{2}$ and the Gaussian curvature is $\bar{c}_{\mathrm{G}}^{2}=c_{1} c_{2}$, with $c_{1}=1 / R_{1}$ and $c_{2}=1 / R_{2}$ being the principal curvatures (see Fig. 1 ). Curvature is defined as positive for convex surfaces (normal, oil-in-water) and negative for concave surfaces (inverted, water-in-oil). The elastic constants are the mean-curvature modulus (or bending rigidity), $k_{\mathrm{c}}$, the Gaussian (or saddle-splay) modulus, $\bar{k}_{\mathrm{c}}$, and the spontaneous (or intrinsic) curvature, $c_{\mathrm{o}}$. For a flat (i.e., noncurved) monolayer reference surface, the elastic free energy is $\Delta G_{\mathrm{c}}(0,0)=\frac{1}{2} k_{\mathrm{c}} A c_{\mathrm{o}}^{2}$, which represents the curvature frustration of the lipids when they are forced into a planar configuration. For a symmetrical bilayer, the spontaneous curvature is zero: $c_{\mathrm{o}}^{(\mathrm{b})}=0$, but the individual monolayer leaflets still experience the frustrated spontaneous curvature stress. It is the latter that provides the driving force for formation of non-lamellar phases, such as the cubic, QII, and inverted hexagonal, $\mathrm{H}_{\text {II }}$, phases (Seddon, 1990).

The mean-curvature modulus, $k_{\mathrm{c}}^{(\mathrm{b})}$, of lipid bilayers has been measured mostly either from analysis of thermally induced bending fluctuations (Engelhardt et al., 1985; Bivas et al., 1987), or more recently from an adaptation of the pipette-aspiration techniques that are used routinely to determine the membrane area dilation mod- uli of giant vesicles (Evans and Rawicz, 1990). Methods have been developed to measure the mean curvature modulus, $k_{\mathrm{c}}^{(\mathrm{m})}$, of lipid monolayers that are based on the response of $\mathrm{H}_{\mathrm{II}}$-phase dimensions to dual-solvent stress (Rand et al., 1990; Leikin et al., 1996). Some progress has also been made recently in the estimation of the Gaussian curvature modulus, $\bar{k}_{\mathrm{c}}^{(\mathrm{m})}$, for lipid monolayers, based either on the response of cubic $\mathrm{Q}_{\mathrm{II}}$-phase dimensions to varying water content (Templer et al., 1998), or on observation of $\mathrm{L}_{\alpha}-\mathrm{Q}_{\text {II }}$ phase coexistence (Siegel and Kozlov, 2004).

At the time of compilation of my "Handbook of Lipid Bilayers" (Marsh, 1990), relatively little information was available on the elastic bending constants of lipid assemblies. This situation has now changed considerably, and it is the purpose of this communication to bring together the data that are currently available on elastic bending constants. There is also some merit in presenting together data from both bilayers and monolayers, so that they can be compared on a mutually consistent basis. Where appropriate, values of monolayer spontaneous curvature are also included.

\section{Elastic moduli: definitions and useful relations}

\subsection{Definitions}

The mean curvature modulus can be defined in terms of the derivative of the mean bending moment per unit length, $\bar{M}=k_{\mathrm{c}} \bar{c}$, with respect to the mean curvature:

$k_{\mathrm{c}}=\left(\frac{\partial \bar{M}}{\partial \bar{c}}\right)_{\mathrm{A}, \bar{c}_{\mathrm{G}}}$

An alternative definition is in terms of the free energy of bending, $\delta \Delta G_{\mathrm{c}}=\frac{1}{2} A \bar{M} \bar{c}$ :

$k_{\mathrm{c}}=\frac{1}{A}\left(\frac{\partial^{2} \Delta G_{\mathrm{c}}}{\partial \bar{c}^{2}}\right)_{\mathrm{A}, \bar{c}_{\mathrm{G}}}$

which derives directly from Eq. (1). In terms of the profile, $p(z)=\partial \pi(z) / \partial z$, of the local lateral pressure, $\pi(z)$, within the membrane (or monolayer), the mean curvature modulus is related to the first moment of the pressure profile of the bent monolayer (Szleifer et al., 1990):

$k_{\mathrm{c}}=-\int \frac{\partial p(z)}{\partial \bar{c}} z \mathrm{~d} z$

where $z$ is the distance from the bilayer mid-plane, or equivalent. The integration limits must cover all regions for which $p(z) \neq 0$ : essentially from 0 to $d$ for a monolayer and from $-d$ to $+d$ for a bilayer, where $d$ is the 
monolayer thickness including the associated hydration layer.

The Gaussian curvature modulus can be defined analogously in terms of a Gaussian bending moment per unit length, $\bar{M}_{\mathrm{G}}=\bar{k}_{\mathrm{c}} \bar{c}_{\mathrm{G}}$ :

$\bar{k}_{\mathrm{c}}=\left(\frac{\partial \bar{M}_{\mathrm{G}}}{\partial \bar{c}_{\mathrm{G}}}\right)_{\mathrm{A}, \bar{c}}$

The definition in terms of the elastic free energy, $\delta \Delta G_{\mathrm{c}}=$ $A \bar{M}_{\mathrm{G}} \bar{c}_{\mathrm{G}}$, is

$\bar{k}_{\mathrm{c}}=\frac{1}{A}\left(\frac{\partial \Delta G_{\mathrm{c}}}{\partial \bar{c}_{\mathrm{G}}^{2}}\right)_{\mathrm{A}, \bar{c}}$

which again is obtained directly from Eq. (1). In terms of the local lateral pressure profile, the Gaussian curvature modulus is determined by the second moment (Helfrich, 1981):

$\bar{k}_{\mathrm{c}}=-\int(z-\delta)^{2} p(z) \mathrm{d} z$

where $z=\delta$ is the position of the neutral plane (or plane of inextension). Finally, the spontaneous bending moment per unit length, $M_{\mathrm{O}}=k_{\mathrm{c}} c_{\mathrm{o}}$, corresponds to the first moment of the pressure profile and is given simply by (Helfrich, 1981):

$k_{\mathrm{c}} c_{\mathrm{o}}=\int z p(z) \mathrm{d} z$

The first moment does not depend on the choice of the origin for $z$, because $\int p(z) \mathrm{d} z=0$.

\subsection{Bilayer mean curvature and Gaussian curvature moduli}

All that has been stated so far applies equally to a bilayer or a monolayer. The elastic constants and the location of the neutral surface for each are, of course, different. It is useful to relate the bilayer elastic constants to those of the constituent monolayer leaflets. To do this, the curvature energies of the outer and inner monolayers must be considered explicitly (see Fig. 2). The areas, $A_{\text {out }}$ and $A_{\text {in }}$, at the neutral surfaces of the outer and inner monolayers in a curved bilayer are given by simple geometry:

$A_{\text {out }}=A\left(1+\delta c_{1}\right)\left(1+\delta c_{2}\right)=A\left(1+\delta \bar{c}+\delta^{2} \bar{c}_{\mathrm{G}}^{2}\right)$

and

$A_{\text {in }}=A\left(1-\delta c_{1}\right)\left(1-\delta c_{2}\right)=A\left(1-\delta \bar{c}+\delta^{2} \bar{c}_{\mathrm{G}}^{2}\right)$

where $A, \bar{c}$ and $\bar{c}_{\mathrm{G}}^{2}$ are the area, the mean curvature and the Gaussian curvature, respectively, at the bilayer midplane, and $\delta$ is the distance of the neutral surface from

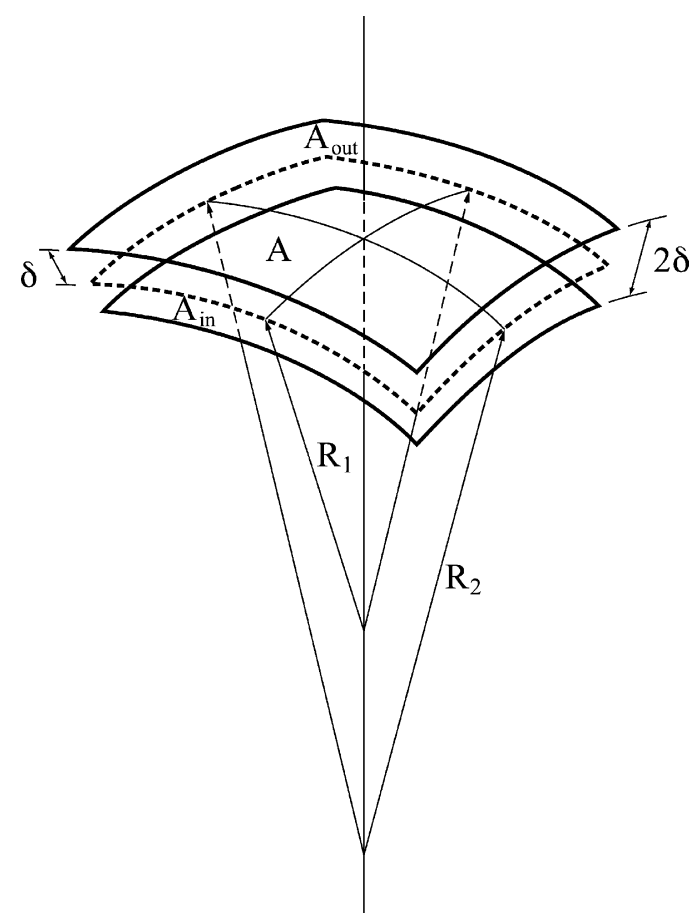

Fig. 2. Geometry of outer (out) and inner (in) monolayers in a curved bilayer vesicle. Curvatures of the two neutral surfaces are given by $c_{1,2}^{\text {out }}=1 /\left(R_{1,2}+\delta\right)$ and $c_{1,2}^{\text {in }}=-1 /\left(R_{1,2}-\delta\right)$, where $R_{1,2}$ are the principal radii of curvature of the bilayer mid-plane and $\delta$ is the distance of the neutral surface from the bilayer mid-plane. Areas at the two neutral surfaces are $A_{\text {out }}=A\left(1+\delta c_{1}\right)\left(1+\delta c_{2}\right)$ and $A_{\text {in }}=A\left(1-\delta c_{1}\right)\left(1-\delta c_{2}\right)$, where $A$ is the corresponding area at the bilayer mid-plane, and $c_{1}$ and $c_{2}$ are the principal curvatures of the mid-plane.

the mid-plane. The mean curvatures, $\bar{c}_{\text {out }}$ and $\bar{c}_{\text {in }}$, of the neutral surfaces of the outer and inner monolayers are then given by

$\bar{c}_{\text {out }}=\left(\frac{1}{R_{1}+\delta}+\frac{1}{R_{2}+\delta}\right)=\left(\bar{c}+2 \delta \bar{c}_{\mathrm{G}}^{2}\right) \frac{A}{A_{\text {out }}}$

and

$\bar{c}_{\text {in }}=-\left(\frac{1}{R_{1}-\delta}+\frac{1}{R_{2}-\delta}\right)=-\left(\bar{c}-2 \delta \bar{c}_{\mathrm{G}}^{2}\right) \frac{A}{A_{\text {in }}}$

The Gaussian curvatures, $\bar{c}_{\mathrm{G} \text {,out }}^{2}$ and $\bar{c}_{\mathrm{G} \text {,in }}^{2}$, at the neutral surfaces of the outer and inner monolayers are given similarly by

$\bar{c}_{\mathrm{G}, \text { out }}^{2}=\frac{1}{\left(R_{1}+\delta\right)\left(R_{2}+\delta\right)}=\bar{c}_{\mathrm{G}}^{2} \frac{A}{A_{\text {out }}}$

and

$\bar{c}_{\mathrm{G}, \text { in }}^{2}=\frac{1}{\left(R_{1}-\delta\right)\left(R_{2}-\delta\right)}=\bar{c}_{\mathrm{G}}^{2} \frac{A}{A_{\text {in }}}$ 
where in each case $A_{\text {out }}$ and $A_{\text {in }}$ are given by Eqs. (9) and (10), respectively.

For a symmetrical bilayer, the bending moduli and spontaneous curvatures of the two constituent monolayers are equal, i.e., $k_{\mathrm{c} \text {,out }}=k_{\mathrm{c} \text {,in }} \equiv k_{\mathrm{c}}^{(\mathrm{m})}, \bar{k}_{\mathrm{c} \text {,out }}=\bar{k}_{\mathrm{c} \text {,in }} \equiv$ $\bar{k}_{\mathrm{c}}^{(\mathrm{m})}$ and $c_{\mathrm{o} \text {,out }}=c_{\mathrm{o}, \text { in }} \equiv c_{\mathrm{o}}$. Adding free energy contributions from the outer and inner monolayers of the bilayer membrane according to Eq. (1), and discarding terms of fourth order or higher in the membrane curvature, $\bar{c}$ and $\bar{c}_{\mathrm{G}}$, then gives the following expression for the total bending free energy of the bilayer:

$$
\begin{aligned}
\Delta G_{\mathrm{c}}^{(\mathrm{b})}\left(\bar{c}, \bar{c}_{\mathrm{G}}\right)= & k_{\mathrm{c}}^{(\mathrm{m})} A\left(\bar{c}^{2}+c_{\mathrm{o}}^{2}\right) \\
& +2\left(\bar{k}_{\mathrm{c}}^{(\mathrm{m})}-2 k_{\mathrm{c}}^{(\mathrm{m})} \delta c_{\mathrm{o}}+\frac{1}{2} k_{\mathrm{c}}^{(\mathrm{m})} \delta^{2} c_{\mathrm{o}}^{2}\right) A \bar{c}_{\mathrm{G}}^{2}
\end{aligned}
$$

which assumes that the two constituent monolayers are not mutually coupled, i.e., are free to slide over one another. Comparison of Eq. (15) with Eq. (1) shows that the curvature moduli, $k_{\mathrm{c}}^{(\mathrm{b})}$ and $\bar{k}_{\mathrm{c}}^{(\mathrm{b})}$, for the bilayer are given by (cf. Petrov and Bivas, 1984):

$k_{\mathrm{c}}^{(\mathrm{b})}=2 k_{\mathrm{c}}^{(\mathrm{m})}$

$\bar{k}_{\mathrm{c}}^{(\mathrm{b})}=2\left(\bar{k}_{\mathrm{c}}^{(\mathrm{m})}-2 k_{\mathrm{c}}^{(\mathrm{m})} \delta c_{\mathrm{o}}\left(1-\frac{1}{4} \delta c_{\mathrm{o}}\right)\right)$

where the curvature moduli with superscript (m) correspond to the lipid monolayer. The Gaussian curvature modulus for a bilayer involves not only the two curvature moduli, $k_{\mathrm{c}}^{(\mathrm{m})}$ and $\bar{k}_{\mathrm{c}}^{(\mathrm{m})}$, of the component monolayers, but also their spontaneous curvature, $c_{\mathrm{o}}$. Note that the constant term $k_{\mathrm{c}}^{(\mathrm{m})} A c_{\mathrm{o}}^{2}$ on the right of Eq. (15) represents curvature frustration of the individual apposing monolayers and does not contribute to the energy of bending a symmetrical bilayer. It is conventionally omitted because the resultant spontaneous curvature vanishes for a symmetrical bilayer: $c_{\mathrm{o}}^{(\mathrm{b})}=0$.

In the above treatment, the monolayer leaflets of the bilayer are assumed to be uncoupled. Monolayer coupling has been treated in an alternative approach that considers different explicit models for the lateral pressure distribution across the bilayer (Helfrich, 1974; Bloom et al., 1991). All predict that the bending modulus should depend linearly on the area extension modulus, $K_{\mathrm{A}}$, and scale as the square of the membrane (or monolayer) thickness. The neutral surface of inextension during bending is located at the bilayer mid-plane. If the pressure profile is modeled by two thin, extensible shells at distance $d_{\mathrm{m}}$ from the neutral plane, the mean curvature modulus is given by

$k_{\mathrm{c}}^{(\mathrm{b})}=2 k_{\mathrm{c}}^{(\mathrm{m})}=K_{\mathrm{A}}^{(\mathrm{m})} d_{\mathrm{m}}^{2}$ where $K_{\mathrm{A}}^{(\mathrm{m})}$ is the area extension elastic modulus for one of the thin (monolayer) shells, and the two monolayers are uncoupled. If the two monolayer thin shells are coupled, then:

$k_{\mathrm{c}}^{(\mathrm{b})}=\frac{1}{4} K_{\mathrm{A}}^{(\mathrm{b})} d_{\mathrm{b}}^{2} \equiv 2 K_{\mathrm{A}}^{(\mathrm{m})} d_{\mathrm{m}}^{2}$

where $K_{\mathrm{A}}^{(\mathrm{b})}\left(\equiv 2 K_{\mathrm{A}}^{(\mathrm{m})}\right)$ is the area extension elastic modulus for a bilayer and $d_{\mathrm{b}}=2 d_{\mathrm{m}}$. Thus, for the coupled case, the bending modulus is four times that of the putative isolated monolayer, in this model. If instead the lateral pressure distribution is uniform with depth in the membrane, integration over the monolayer thickness yields:

$k_{\mathrm{c}}^{(\mathrm{b})}=2 k_{\mathrm{c}}^{(\mathrm{m})}=\frac{1}{6} K_{\mathrm{t}} d_{\mathrm{m}}^{3}=\frac{1}{6} K_{\mathrm{A}}^{(\mathrm{m})} d_{\mathrm{m}}^{2}$

for uncoupled monolayers, where $K_{\mathrm{t}}$ is the elastic modulus for the monolayer thickness, and volume compressibility is neglected in the final equality. Similarly, for coupled monolayers and a uniform stress distribution, the corresponding integration across the membrane thickness yields:

$k_{\mathrm{c}}^{(\mathrm{b})}=\frac{1}{12} K_{\mathrm{t}} d_{\mathrm{b}}^{3}=\frac{1}{12} K_{\mathrm{A}}^{(\mathrm{b})} d_{\mathrm{b}}^{2} \equiv \frac{2}{3} K_{\mathrm{A}}^{(\mathrm{m})} d_{\mathrm{m}}^{2}$

In this case, the bending modulus of the coupled bilayer is eight times that of the putative isolated monolayer.

\subsection{Monolayer mean curvature modulus and} $H_{\text {II-phases }}$

The bending constants for a monolayer leaflet that are determined from dual-solvent stress experiments on

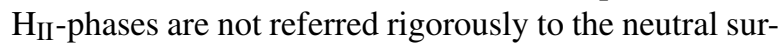
face but to the so-called pivotal plane (Rand et al., 1990). The pivotal plane is the position along the lipid molecule at which the cross-sectional area does not change with increasing water content in the $\mathrm{H}_{\mathrm{II}}$-phase. Leikin et al. (1996) have derived the relation between the elastic constants referred to the pivotal plane and those referred to the neutral plane (which apply generally to other geometries).

The neutral plane is the surface at which bending takes place without area extension. Referred to the neutral surface, the elastic free energy including stretching is, for cylindrical geometry (Kozlov and Winterhalter, 1991):

$$
\Delta G_{\mathrm{el}}=\frac{1}{2} k_{\mathrm{c}, \mathrm{n}} A_{\mathrm{o}, \mathrm{n}}\left(\bar{c}_{\mathrm{n}}-c_{\mathrm{o}, \mathrm{n}}\right)^{2}+\frac{1}{2} K_{\mathrm{A}} \frac{\left(A_{\mathrm{n}}-A_{\mathrm{o}, \mathrm{n}}\right)^{2}}{A_{\mathrm{o}, \mathrm{n}}}
$$

where $A_{\mathrm{n}}$ is the area after stretching, $A_{\mathrm{o}, \mathrm{n}}$ the equilibrium area without bending, and $K_{\mathrm{A}}$ is the elastic modulus for area extension. In Eq. (22), the subscript $n$ indicates quantities defined at the neutral plane. The area 
per lipid molecule at a given cylindrical surface in the $\mathrm{H}_{\mathrm{II}}$-phase is directly proportional to the curvature of that surface (Leikin et al., 1996). Hence, at constant water content: $\partial \bar{c}_{\mathrm{n}} / \partial A_{\mathrm{n}}=\bar{c}_{\mathrm{n}} / A_{\mathrm{n}}$. From Eq. (22), the condition for mechanical equilibrium $\left(\partial \Delta G_{\mathrm{el}} / \partial A_{\mathrm{n}}=0\right)$ at constant water content then leads to the following result for the area per lipid molecule at the neutral surface (Leikin et al., 1996):

$A_{\mathrm{n}}=A_{\mathrm{o}, \mathrm{n}}\left(1-\frac{k_{\mathrm{c}, \mathrm{n}} c_{\mathrm{o}, \mathrm{n}}}{K_{\mathrm{A}}}\left(\bar{c}_{\mathrm{n}}-c_{\mathrm{o}, \mathrm{n}}\right)\right)$

Eq. (23) is taken only up to first order in $\bar{c}_{\mathrm{n}}$, which is consistent with the harmonic elastic approximation (i.e., Eq. (22)). Substituting Eq. (23) into Eq. (22) then gives the equilibrium elastic free energy:

$\Delta G_{\mathrm{el}}=\frac{1}{2} k_{\mathrm{c}, \mathrm{n}}\left(1+k_{\mathrm{c}, \mathrm{n}} \frac{c_{\mathrm{o}, \mathrm{n}}^{2}}{K_{\mathrm{A}}}\right) A_{\mathrm{o}, \mathrm{n}}\left(\bar{c}_{\mathrm{n}}-c_{\mathrm{o}, \mathrm{n}}\right)^{2}$

which represents one form of renormalization of the bending rigidity, $k_{\mathrm{c}, \mathrm{n}}$.

The corresponding expression for the equilibrium elastic free energy, in terms of quantities referred to the pivotal plane, is (Leikin et al., 1996):

$\Delta G_{\mathrm{el}}=\frac{1}{2} k_{\mathrm{c}, \mathrm{p}} A_{\mathrm{p}}\left(\bar{c}_{\mathrm{p}}-c_{\mathrm{o}, \mathrm{p}}\right)^{2}$

where $A_{\mathrm{p}}$ is the area at the pivotal plane that is defined by

$$
\left(\frac{\partial A_{\mathrm{p}}}{\partial \bar{c}_{\mathrm{n}}}\right)_{\bar{c}_{\mathrm{n}}=c_{\mathrm{o}, \mathrm{n}}}=0
$$

The pivotal plane is of considerable practical importance because this is the reference surface that is used for analysing the dependence of $\mathrm{H}_{\mathrm{II}}$-phase dimensions on dual solvent stress (Gruner et al., 1986; Rand et al., 1990). In Eqs. (25) and (26), the subscript p indicates quantities defined at the pivotal plane and the subscript $\mathrm{n}$ those defined at the neutral plane. The geometric relation between the areas at the pivotal and neutral planes is simply:

$A_{\mathrm{p}}^{2}=A_{\mathrm{n}}^{2}+2\left(V_{\mathrm{p}}-V_{\mathrm{n}}\right) A_{\mathrm{n}} \bar{c}_{\mathrm{n}}$

where $V_{\mathrm{p}}-V_{\mathrm{n}}$ is the volume between the pivotal and neutral planes. To lowest order, the area at the pivotal plane is then given by (Leikin et al., 1996):

$A_{\mathrm{p}}=A_{\mathrm{o}, \mathrm{n}} \sqrt{\frac{1+k_{\mathrm{c}, \mathrm{n}} c_{\mathrm{o}, \mathrm{n}}^{2} / K_{\mathrm{A}}}{1-k_{\mathrm{c}, \mathrm{n}} c_{\mathrm{o}, \mathrm{n}}^{2} / K_{\mathrm{A}}}}$

From the geometrical relation: $A_{\mathrm{p}} \bar{c}_{\mathrm{p}}=A_{\mathrm{n}} \bar{c}_{\mathrm{n}}$ (cf. Eqs. (11) and (12)), the spontaneous curvature at the pivotal plane also is given by

$c_{\mathrm{o}, \mathrm{p}}=c_{\mathrm{o}, \mathrm{n}} \sqrt{\frac{1-k_{\mathrm{c}, \mathrm{n}} c_{\mathrm{o}, \mathrm{n}}^{2} / K_{\mathrm{A}}}{1+k_{\mathrm{c}, \mathrm{n}} c_{\mathrm{o}, \mathrm{n}}^{2} / K_{\mathrm{A}}}}$

Substituting Eqs. (28) and (29) in Eq. (25) then gives the following expression for the elastic free energy:

$$
\Delta G_{\mathrm{el}}=\frac{1}{2} k_{\mathrm{c}, \mathrm{p}} \frac{\left(1-k_{\mathrm{c}, \mathrm{n}} c_{\mathrm{o}, \mathrm{n}}^{2} / K_{\mathrm{A}}\right)^{5 / 2}}{\left(1+k_{\mathrm{c}, \mathrm{n}} c_{\mathrm{o}, \mathrm{n}}^{2} / K_{\mathrm{A}}\right)^{3 / 2}} A_{\mathrm{o}, \mathrm{n}}\left(\bar{c}_{\mathrm{n}}-c_{\mathrm{o}, \mathrm{n}}\right)^{2}
$$

Comparison of Eqs. (24) and (30), finally reveals the relationship between the mean curvature moduli referred to the pivotal and neutral planes:

$k_{\mathrm{c}, \mathrm{p}}=k_{\mathrm{c}, \mathrm{n}} \frac{\left(1+k_{\mathrm{c}, \mathrm{n}} c_{\mathrm{o}, \mathrm{n}}^{2} / K_{\mathrm{A}}\right)^{3 / 2}}{\left(1-k_{\mathrm{c}, \mathrm{n}} c_{\mathrm{o}, \mathrm{n}}^{2} / K_{\mathrm{A}}\right)^{5 / 2}}$

For $k_{\mathrm{c}, \mathrm{n}} c_{\mathrm{o}, \mathrm{n}}^{2} / K_{\mathrm{A}} \ll 1$, the following approximations hold:

$k_{\mathrm{c}, \mathrm{n}} \approx\left(1-4 k_{\mathrm{c}, \mathrm{p}} \frac{c_{\mathrm{o}, \mathrm{p}}^{2}}{K_{\mathrm{A}}}\right) k_{\mathrm{c}, \mathrm{p}}$

and

$c_{\mathrm{o}, \mathrm{n}} \approx\left(1+k_{\mathrm{c}, \mathrm{p}} \frac{c_{\mathrm{o}, \mathrm{p}}^{2}}{K_{\mathrm{A}}}\right) c_{\mathrm{o}, \mathrm{p}}$

which yield corrections of up to $15-40 \%$ for the mean curvature modulus, but of only $3-10 \%$ for the spontaneous curvature (Leikin et al., 1996).

\subsection{Renormalization of the mean curvature modulus}

Bending and stretching are energetically uncoupled from one another when they are expressed at the neutral surface. Nonetheless, Helfrich and Kozlov (1993) have pointed out that the lateral tension associated with bending can reduce the elastic resistance to curvature, when the latter is not uniform. This is especially the case for membrane fluctuations (Hønger et al., 1994). The elastic free energy including stretching is then, for cylindrical geometry:

$\Delta G_{\mathrm{el}}=\frac{1}{2} k_{\mathrm{c}} A\left(\bar{c}-c_{\mathrm{o}}\right)^{2}+\frac{1}{2} K_{\mathrm{A}} \frac{\left(A-A_{\mathrm{o}}\right)^{2}}{A_{\mathrm{o}}}$

where $A$ appears in the free energy of bending, instead of $A_{\mathrm{o}}$ (cf. Eq. (22)). The coupling arises because the lipid molecules are free to shift relative to the neutral surface (Helfrich and Kozlov, 1993). The resulting effective 
equilibrium area is given by $\left(\partial \Delta G_{\mathrm{el}} / \partial A\right)_{\bar{c}}=0$ :

$A=A_{\mathrm{o}}\left(1-\frac{1}{2} \frac{k_{\mathrm{c}}}{K_{\mathrm{A}}}\left(\bar{c}-c_{\mathrm{o}}\right)^{2}\right)$

where the derivative is evaluated at constant curvature, $\bar{c}$. Substituting Eq. (35) into Eq. (34) and retaining only terms up to $\bar{c}^{2}$ in the membrane curvature (consistent with the harmonic approximation) leads to an apparent reduction in the bending free energy. This reduction is characterized by an effective rescaling of the experimental mean curvature modulus according to (Helfrich and Kozlov, 1993):

$k_{\mathrm{c}}=k_{\mathrm{c}}^{\mathrm{o}}\left(1-\frac{k_{\mathrm{c}}^{\mathrm{o}}}{K_{\mathrm{A}}} c_{\mathrm{o}}^{2}\right)$

where $k_{\mathrm{c}}^{\mathrm{o}}$ is the bare modulus of mean curvature that characterizes pure bending. In the absence of spontaneous curvature, the bending energy is reduced by higher order terms for strong curvatures (Helfrich and Kozlov, 1993). An expression equivalent to Eq. (36), viz., $k_{\mathrm{c}}=k_{\mathrm{c}}^{\mathrm{o}}\left(1-r^{2} / K_{\mathrm{A}}\right)$, has been derived by Hønger et al. (1994) specifically for the coupling of bending with membrane density fluctuations, where $r$ is a phenomenological coupling constant. Experimentally, a decrease in $k_{\mathrm{c}}$ is found on approaching the fluid-gel phase transition at which the lateral compressibility, $1 / K_{\mathrm{A}}$, is expected to diverge (Chu et al., 2005).

\subsection{Gaussian curvature modulus}

The relationship between the mean curvature and Gaussian curvature moduli can be obtained by consideration of the anisotropy of the membrane stresses, which is parameterized for solids by Poisson's ratio, $\sigma$. In such an anisotropic coupled system, the principal bending moments per unit length, $M_{1}$ and $M_{2}$, are given by (see, e.g., Southwell, 1941; Evans and Skalak, 1980):

$M_{1}=k_{\mathrm{c}}\left(c_{1}+\sigma c_{2}\right)$

and

$M_{2}=k_{\mathrm{c}}\left(c_{2}+\sigma c_{1}\right)$

The elastic free energy of bending (ignoring spontaneous curvature) is then given by

$$
\begin{aligned}
\Delta G_{\mathrm{c}}= & \frac{1}{2} A\left(M_{1} c_{1}+M_{2} c_{2}\right)=\frac{1}{2} k_{\mathrm{c}} A\left(c_{1}+c_{2}\right)^{2} \\
& -k_{\mathrm{c}}(1-\sigma) A c_{1} c_{2}
\end{aligned}
$$

Comparison with Eq. (1) then leads immediately to the following relation between the elastic moduli:

$\bar{k}_{\mathrm{c}}=-(1-\sigma) k_{\mathrm{c}}$ where $\sigma$ is the ratio of the fractional linear extension within the membrane plane to the fractional contraction in membrane thickness, in response to isotropic membrane tension. Assuming volume incompressibility results in the maximum value of $\sigma$ (viz., $\sigma \leq 0.5$ ) for a solid, which therefore yields $\bar{k}_{\mathrm{c}} / k_{\mathrm{c}} \leq-0.5$. For a solid the minimum value of $\sigma$ is: $\sigma=0$ which corresponds to $\bar{k}_{\mathrm{c}}=-k_{\mathrm{c}}$.

\section{Compilations and discussion}

All tables use standard ICBN abbreviations for the lipid species, as defined in the footnotes (see also Marsh, 1990).

\subsection{Bilayer membranes}

Table 1 gives the mean curvature moduli, $k_{\mathrm{c}}^{(\mathrm{b})}$, for different phospholipid bilayers that are determined from the entropic tension of bending fluctuations in giant lipid vesicles by using pipette aspiration experiments. The values mostly represent a consistent set of measurements from a single laboratory. The bending rigidities clearly depend on the bilayer thickness, whereas the area extension moduli, $K_{\mathrm{A}}$ (also included in Table 1) are almost independent of bilayer thickness, after they have been corrected for renormalization by the thermal bending fluctuations (see Evans and Rawicz, 1990). As demonstrated by the original authors, and is seen from the final column in Table $1,\left(k_{\mathrm{c}} / K_{\mathrm{A}}\right)^{1 / 2}$ depends linearly on the bilayer thickness, $d_{\mathrm{t}}$, in accordance with Eqs. (18)-(21). The exception is that lipids containing polyunsaturated chains have anomalously low bending rigidities. Linear extrapolation reveals that the effective bilayer thickness is given by: $d_{\mathrm{t}}=h_{\mathrm{pp}}-1.0 \mathrm{~nm}$, where $h_{\mathrm{pp}}$ is the separation between the phosphate peaks in the transbilayer electron density profile (Rawicz et al., 2000). The increase in $k_{\mathrm{c}}^{(\mathrm{b})}$ on addition of cholesterol corresponds to the increase in the area extension modulus $K_{\mathrm{A}}^{(\mathrm{b})}$ according to Eqs. (18)-(21). The bending rigidities, $k_{\mathrm{c}}^{(\mathrm{m})}$, predicted for an (uncoupled) lipid monolayer according to Eq. (16) by using the experimental bilayer values are given in parentheses in Table 1.

Table 2 gives the mean curvature moduli, $k_{\mathrm{c}}^{(\mathrm{b})}$, for different phospholipid bilayers that are determined from the thermally excited shape fluctuations (flicker phenomena) of giant unilamellar bilayer vesicles. The data collected with this method originate from two separate laboratories. In general, the values of the bending rigidity found by this technique are consistently larger than those obtained from pipette aspiration experiments (cf. 
Table

Elastic bending constants, $k_{\mathrm{c}}^{(\mathrm{b})}$, for giant unilamellar bilayer vesicles, measured by pipette aspiration experiments (Rawicz et al., 2000; Evans and Rawicz, 1990; McIntosh et al., 1995) ${ }^{\text {a }}$

\begin{tabular}{|c|c|c|c|c|c|c|}
\hline Lipid $^{\text {b }}$ & $T\left({ }^{\circ} \mathrm{C}\right)$ & $k_{\mathrm{c}}^{(\mathrm{b})}\left(\times 10^{-19} \mathrm{~J}\right)$ & $k_{\mathrm{c}}^{(\mathrm{m})}\left(\times 10^{-19} \mathrm{~J}\right)$ & $K_{\mathrm{A}}^{(\mathrm{b})}\left(\mathrm{mN} \mathrm{m}^{-1}\right)$ & $d_{\mathrm{t}}=h_{\mathrm{pp}}-1.0(\mathrm{~nm})$ & $k_{\mathrm{c}}^{(\mathrm{b})} /\left(K_{\mathrm{A}}^{(\mathrm{b})} d_{\mathrm{t}}^{2}\right)$ \\
\hline $\operatorname{diC}(13: 0)$ PtdCho & 22 & $0.56 \pm 0.07$ & $(0.28 \pm 0.04)$ & $239 \pm 15$ & $2.41 \pm 0.05$ & $0.040 \pm 0.009$ \\
\hline $\operatorname{diC}(14: 0) \operatorname{PtdCho}$ & 29 & $0.56 \pm 0.06$ & $(0.28 \pm 0.03)$ & $234 \pm 23$ & $2.52 \pm 0.06$ & $0.038 \pm 0.009$ \\
\hline $\mathrm{C}(18: 0) /\left(18: 1 \mathrm{c} \Delta^{9}\right) \mathrm{PtdCho}$ & 18 & $0.90 \pm 0.06$ & $(0.45 \pm 0.03)$ & $235 \pm 14$ & $3.07 \pm 0.06$ & $0.041 \pm 0.007$ \\
\hline $\mathrm{C}\left(18: 1 \mathrm{c} \Delta^{9}\right) /(18: 0)$ PtdCho & 18 & $0.92 \pm 0.07$ & $(0.46 \pm 0.04)$ & $230 \pm 10$ & & \\
\hline $\operatorname{diC}\left(18: 1 \mathrm{c} \Delta^{9}\right) \operatorname{PtdCho}$ & 18 & $0.85 \pm 0.10$ & $(0.42 \pm 0.05)$ & $265 \pm 18$ & $2.69 \pm 0.04$ & $0.044 \pm 0.004$ \\
\hline $\operatorname{diC}\left(18: 1 \mathrm{t} \Delta^{9}\right) \operatorname{PtdCho}$ & 18 & $1.03 \pm 0.11$ & $(0.51 \pm 0.05)$ & $229 \pm 12$ & & \\
\hline $\operatorname{diC}\left(18: 1 \mathrm{c} \Delta^{6}\right) \operatorname{PtdCho}$ & 18 & $0.90 \pm 0.09$ & $(0.45 \pm 0.05)$ & $235 \pm 18$ & & \\
\hline $\mathrm{C}(18: 0) /\left(18: 2 \mathrm{c} \Delta^{9,12}\right)$ PtdCho & 18 & $0.46 \pm 0.07$ & $(0.23 \pm 0.04)$ & $241 \pm 22$ & & \\
\hline $\operatorname{diC}\left(18: 2 \mathrm{c} \Delta^{9,12}\right) \operatorname{PtdCho}$ & 18 & $0.44 \pm 0.07$ & $(0.22 \pm 0.04)$ & $247 \pm 21$ & $2.49 \pm 0.03$ & $0.029 \pm 0.008$ \\
\hline $\operatorname{diC}\left(18: 3 c \Delta^{9,12,15}\right) \operatorname{PtdCho}$ & 18 & $0.38 \pm 0.04$ & $(0.19 \pm 0.02)$ & $244 \pm 32$ & $2.43 \pm 0.06$ & $0.026 \pm 0.008$ \\
\hline \multirow[t]{2}{*}{$\operatorname{diC}\left(20: 4 \mathrm{c} \Delta^{5,8,11,14}\right)$ PtdCho } & 18 & $0.44 \pm 0.05$ & $(0.22 \pm 0.03)$ & $250 \pm 10$ & $2.42 \pm 0.07$ & $0.030 \pm 0.006$ \\
\hline & 14 & $0.28 \pm 0.08$ & $(0.14 \pm 0.04)$ & & & \\
\hline $\operatorname{diC}\left(22: 1 \mathrm{c} \Delta^{13}\right) \operatorname{Ptd} C h o$ & 18 & $1.20 \pm 0.15$ & $(0.60 \pm 0.08)$ & $263 \pm 10$ & $3.37 \pm 0.05$ & $0.040 \pm 0.008$ \\
\hline Egg PtdCho & 14 & $0.51 \pm 0.15$ & $(0.26 \pm 0.07)$ & & & \\
\hline $\mathrm{Gal}_{2} \mathrm{acyl}_{2} \mathrm{Gro}$ & 23 & $0.44 \pm 0.03$ & $(0.22 \pm 0.02)$ & & & \\
\hline $\mathrm{C}(18: 0) /\left(18: 1 \mathrm{c} \Delta^{9}\right) \mathrm{PtdCho} /$ cholesterol $(1: 1 \mathrm{~mol} / \mathrm{mol})$ & 15 & $2.46 \pm 0.39$ & $(1.23 \pm 0.20)$ & $640 \pm 32^{\mathrm{c}}$ & & \\
\hline Egg PtdCho/C $\left(18: 1 \mathrm{c} \Delta^{9}\right)$ lyso PtdCho $(1: 1 \mathrm{~mol} / \mathrm{mol})$ & 14 & $0.13 \pm 0.02$ & $(0.06 \pm 0.01)$ & & & \\
\hline
\end{tabular}

${ }^{a} k_{\mathrm{c}}^{(\mathrm{m})}$ is the mean curvature modulus for a monolayer that is predicted from the experimental bilayer value by using Eq. (16) for $u n c o u p l e d$ monolayers; $K_{\mathrm{A}}^{(\mathrm{b})}$ is the area extension modulus that has been corrected for fluctuations (Evans and Rawicz, 1990; Rawicz et al., 2000); and $h_{\mathrm{pp}}$ is the separation between phosphate peaks in the transbilayer electron density profile (Rawicz et al., 2000).

${ }^{\mathrm{b}} \mathrm{C}(18: 0) /\left(18: 1 \mathrm{c} \Delta^{9}\right) \mathrm{PtdCho}$ is 1-stearoyl-2-oleoyl-sn-glycero-3-phosphocholine and $\mathrm{C}\left(18: 1 \mathrm{c} \Delta^{9}\right) /(18: 0) \mathrm{PtdCho}$ is 1-oleoyl-2-stearoyl-sn-glycero-3-phosphocholine, etc.; $\mathrm{C}\left(18: 1 \mathrm{c} \Delta^{9}\right)$ lysoPtdCho is 1-oleoyl-2-lyso-sn-glycero-3-phosphocholine. $\mathrm{Gal}_{2} \mathrm{acyl}_{2}$ Gro is digalactosyl diacylglycerol.

${ }^{c}$ Uncorrected value. 
Table 2

Elastic bending constants, $k_{\mathrm{c}}^{(\mathrm{b})}$, deduced from thermally excited shape fluctuations of giant unilamellar bilayer vesicles ${ }^{\mathrm{a}}$

\begin{tabular}{|c|c|c|c|c|}
\hline Lipid $^{b}$ & $T\left({ }^{\circ} \mathrm{C}\right)$ & $k_{\mathrm{c}}^{(\mathrm{b})}\left(\times 10^{-19} \mathrm{~J}\right)$ & $k_{\mathrm{c}}^{(\mathrm{m})}\left(\times 10^{-19} \mathrm{~J}\right)$ & References \\
\hline $\operatorname{diC}(12: 0)$ PtdCho & 18,24 & $0.92 \pm 0.05$ & $(0.46 \pm 0.03)$ & Fernandez-Puente et al. (1994) \\
\hline \multirow[t]{8}{*}{$\operatorname{diC}(14: 0)$ PtdCho } & 25.0 & $0.8 \pm 0.13$ & $(0.40 \pm 0.07)$ & $\begin{array}{l}\text { Fernandez-Puente et al. (1994) and } \\
\text { Méléard et al. (1997) }\end{array}$ \\
\hline & 25.6 & 0.9 & $(0.45)$ & Fernandez-Puente et al. (1994) \\
\hline & 26 & $1.1 \pm 0.1$ & $(0.55 \pm 0.05)$ & $\begin{array}{l}\text { Fernandez-Puente et al. (1994) and } \\
\text { Méléard et al. (1997) }\end{array}$ \\
\hline & 26 & $0.35-0.65$ & $(0.18-0.33)$ & Engelhardt et al. (1985) \\
\hline & 26.4 & 1.2 & $(0.6)$ & Fernandez-Puente et al. (1994) \\
\hline & 27 & $1.52 \pm 0.06$ & $(0.76 \pm 0.03)$ & $\begin{array}{l}\text { Fernandez-Puente et al. (1994) and } \\
\text { Méléard et al. (1997) }\end{array}$ \\
\hline & 30 & $1.3 \pm 0.08$ & $(0.65 \pm 0.04)$ & $\begin{array}{l}\text { Fernandez-Puente et al. (1994) and } \\
\text { Méléard et al. (1997) }\end{array}$ \\
\hline & 40 & $1.27 \pm 0.09$ & $(0.63 \pm 0.05)$ & $\begin{array}{l}\text { Fernandez-Puente et al. (1994) and } \\
\text { Méléard et al. (1997) }\end{array}$ \\
\hline \multirow[t]{4}{*}{$\operatorname{diC}(16: 0)$ PtdCho } & 42.4 & $0.54 \pm 0.10$ & $(0.26 \pm 0.05)$ & Fernandez-Puente et al. (1994) \\
\hline & 44.4 & $1.85 \pm 0.08$ & $(0.92 \pm 0.04)$ & Fernandez-Puente et al. (1994) \\
\hline & 47.4 & $1.50 \pm 0.09$ & $(0.75 \pm 0.05)$ & Fernandez-Puente et al. (1994) \\
\hline & 49.4 & $1.50 \pm 0.07$ & $(0.75 \pm 0.04)$ & Fernandez-Puente et al. (1994) \\
\hline diPhyPtdCho & R.T. & $1.17 \pm 0.10$ & $(0.59 \pm 0.05)$ & Vitkova et al. (2006) \\
\hline \multirow[t]{4}{*}{ Egg PtdCho } & & 0.4 & $(0.2)$ & Engelhardt et al. (1985) \\
\hline & & 1.1 & $(0.55)$ & Duwe et al. (1987) \\
\hline & & $0.40-0.53$ & $(0.20-0.27)$ & Faucon et al. (1989) \\
\hline & & $1.15 \pm 0.15$ & $(0.58 \pm 0.08)$ & Duwe et al. (1990) \\
\hline (Gal)acyl ${ }_{2}$ Gro & & $0.15-0.4$ & $(0.08-0.2)$ & Duwe et al. (1990) \\
\hline diC(14:0)PtdCho/diC(16:0)PtdCho (1:1 mol/mol) & & $0.38-0.49$ & $(0.19-0.25)$ & Engelhardt et al. (1985) \\
\hline $\operatorname{diC}(14: 0) \mathrm{PtdCho} /$ cholesterol $(1: 0 \mathrm{~mol} / \mathrm{mol})$ & 30 & $1.15 \pm 0.15$ & $(0.58 \pm 0.08)$ & Duwe et al. (1990) \\
\hline $\operatorname{diC}(14: 0)$ PtdCho/cholesterol $(94: 6 \mathrm{~mol} / \mathrm{mol})$ & 29 & $0.28-0.37$ & $(0.14-0.19)$ & Engelhardt et al. (1985) \\
\hline \multirow[t]{6}{*}{$\operatorname{diC}(14: 0)$ PtdCho/cholesterol $(9: 1 \mathrm{~mol} / \mathrm{mol})$} & 24.8 & $0.9 \pm 0.1$ & $(0.45 \pm 0.05)$ & Méléard et al. (1997) \\
\hline & 25.2 & $1.45 \pm 0.06$ & $(0.73 \pm 0.03)$ & Méléard et al. (1997) \\
\hline & 26 & $1.63 \pm 0.07$ & $(0.82 \pm 0.04)$ & Méléard et al. (1997) \\
\hline & 27 & $2.23 \pm 0.07$ & $(1.12 \pm 0.04)$ & Méléard et al. (1997) \\
\hline & 30 & $2.00 \pm 0.1$ & $(1.00 \pm 0.05)$ & Méléard et al. (1997) \\
\hline & 40 & $1.84 \pm 0.09$ & $(0.92 \pm 0.05)$ & Méléard et al. (1997) \\
\hline $\operatorname{diC}(14: 0) \operatorname{PtdCho} /$ cholesterol $(8: 2 \mathrm{~mol} / \mathrm{mol})$ & 30 & $2.1 \pm 0.25$ & $(1.05 \pm 0.13)$ & Duwe et al. (1990) \\
\hline \multirow[t]{4}{*}{$\operatorname{diC}(14: 0) P t d C h o /$ cholesterol $(7: 3 \mathrm{~mol} / \mathrm{mol})$} & 20 & $6.1 \pm 0.2$ & $(3.05 \pm 0.1)$ & Méléard et al. (1997) \\
\hline & 30 & $4.1 \pm 0.25$ & $(2.05 \pm 0.13)$ & Méléard et al. (1997) \\
\hline & 40 & $3.07 \pm 0.13$ & $(1.54 \pm 0.07)$ & Méléard et al. (1997) \\
\hline & 30 & $4.0 \pm 0.8$ & $(2.0 \pm 0.4)$ & Duwe et al. (1990) \\
\hline \multirow[t]{2}{*}{$\operatorname{diC}(14: 0)$ PtdCho/cholesterol $(1: 1 \mathrm{~mol} / \mathrm{mol})$} & 30 & $6.1 \pm 0.3$ & $(3.05 \pm 0.15)$ & Méléard et al. (1997) \\
\hline & 40 & $3.7 \pm 0.3$ & $(1.35 \pm 0.15)$ & Méléard et al. (1997) \\
\hline
\end{tabular}

${ }^{a} k_{\mathrm{c}}^{(\mathrm{m})}$ is the mean curvature modulus for a monolayer that is predicted from the experimental bilayer value by using Eq. (16) for uncoupled monolayers.

b (Gal)acyl ${ }_{2}$ Gro is monogalactosyl diacylglycerol.

Table 1). Determination of the chain length dependence in the fluid phase of three disaturated phosphatidylcholines again reveals that $k_{\mathrm{c}}$ depends quadratically on the membrane thickness (Fernandez-Puente et al., 1994). A systematic investigation of the temperature dependence in the fluid state close to the chain-melting transition reveals the softening of the elastic bending constants that arises at the transition (Fernandez-Puente et al., 1994; Méléard et al., 1997). This renormalization of the mean curvature modulus is characterized by Eq. (36), where the area extension compressibility, $1 / K_{\mathrm{A}}$, diverges at the phase transition (Evans and Kwok, 1982).

Table 3 collects the mean curvature moduli, $k_{\mathrm{c}}^{(\mathrm{b})}$, for different phospholipid bilayers that are determined from bending fluctuations in cylindrical vesicles, and also by several other techniques, including electrodeformation and tether formation. This table includes some of the first measurements of bending elasticity on lipid membranes. The spread of values is considerably greater than those of Table 2. A few measurements on spherical giant 
Table 3

Elastic bending constants, $k_{\mathrm{c}}^{(\mathrm{b})}$, deduced from bending fluctuations of tubular liposomes and other methods ${ }^{\mathrm{a}}$

\begin{tabular}{|c|c|c|c|c|}
\hline Lipid $^{b}$ & $T\left({ }^{\circ} \mathrm{C}\right)$ & $k_{\mathrm{c}}^{(\mathrm{b})}\left(\times 10^{-19} \mathrm{~J}\right)$ & $k_{\mathrm{c}}^{(\mathrm{m})}\left(\times 10^{-19} \mathrm{~J}\right)$ & References \\
\hline \multirow[t]{2}{*}{$\operatorname{diC}(12: 0)$ PtdCho } & & $0.34 \pm 0.07$ & $(0.17 \pm 0.04)$ & Kummrow and Helfrich (1991) \\
\hline & 30 & 0.55 & $(0.28)$ & Kučerka et al. (2005a) \\
\hline \multirow[t]{9}{*}{$\operatorname{diC}(14: 0)$ PtdCho } & 22 & $2.4 \pm 0.4$ & $(1.2 \pm 0.2)$ & Beblik et al. (1985) \\
\hline & 24 & 0.43 & $(0.21)$ & Chu et al. (2005) \\
\hline & 25 & 0.53 & $(0.26)$ & Chu et al. (2005) \\
\hline & 26 & $0.60 \pm 0.03$ & $(0.30 \pm 0.02)$ & Chu et al. (2005) \\
\hline & 27 & 0.65 & $(0.33)$ & Chu et al. (2005) \\
\hline & 28 & 0.65 & $(0.32)$ & Chu et al. (2005) \\
\hline & 30 & 0.69 & $(0.35)$ & Chu et al. (2005) \\
\hline & 35 & 0.69 & $(0.35)$ & Chu et al. (2005) \\
\hline & 40 & 0.63 & $(0.31)$ & Chu et al. (2005) \\
\hline \multirow[t]{10}{*}{$\operatorname{diC}(16: 0)$ PtdCho } & 42.0 & $1.6 \pm 0.4$ & $(0.8 \pm 0.2)$ & Mishima et al. (2001) \\
\hline & 42.2 & $2.4 \pm 0.4$ & $(1.2 \pm 0.2)$ & Mishima et al. (2001) \\
\hline & 43.0 & $3.1 \pm 0.3$ & $(1.6 \pm 0.2)$ & Mishima et al. (2001) \\
\hline & 43.5 & $2.8 \pm 0.4$ & $(1.4 \pm 0.2)$ & Mishima et al. (2001) \\
\hline & 44.0 & $3.2 \pm 0.4$ & $(1.6 \pm 0.2)$ & Mishima et al. (2001) \\
\hline & 44 & $2.0 \pm 0.4$ & $(1.0 \pm 0.2)$ & Beblik et al. (1985) \\
\hline & 44.5 & $2.8 \pm 0.4$ & $(1.4 \pm 0.2)$ & Mishima et al. (2001) \\
\hline & 45.0 & $3.0 \pm 0.4$ & $(1.5 \pm 0.2)$ & Mishima et al. (2001) \\
\hline & 45.5 & $2.2 \pm 0.3$ & $(1.1 \pm 0.15)$ & Mishima et al. (2001) \\
\hline & 46 & $2.2 \pm 0.3$ & $(1.1 \pm 0.15)$ & Mishima et al. (2001) \\
\hline $\operatorname{diC}(18: 0)$ PtdCho & 56.5 & $1.8 \pm 0.3$ & $(0.9 \pm 0.15)$ & Beblik et al. (1985) \\
\hline \multirow[t]{14}{*}{$\operatorname{diC}\left(18: 1 \mathrm{c} \Delta^{9}\right) \operatorname{Ptd}$ Cho } & 13 & $0.36 \pm 0.04$ & $(0.18 \pm 0.02)$ & Niggemann et al. (1995) \\
\hline & 16 & $0.26 \pm 0.01$ & $(0.13 \pm 0.005)$ & Niggemann et al. (1995) \\
\hline & 17 & $0.19 \pm 0.04$ & $(0.09 \pm 0.02)$ & Niggemann et al. (1995) \\
\hline & 18 & $0.27 \pm 0.05$ & $(0.14 \pm 0.02)$ & Niggemann et al. (1995) \\
\hline & 20.5 & $0.14 \pm 0.01$ & $(0.07 \pm 0.01)$ & Niggemann et al. (1995) \\
\hline & 21 & $0.13 \pm 0.01$ & $(0.07 \pm 0.01)$ & Niggemann et al. (1995) \\
\hline & 21 & $0.17 \pm 0.03$ & $(0.08 \pm 0.02)$ & Niggemann et al. (1995) \\
\hline & 23 & $0.24 \pm 0.05$ & $(0.12 \pm 0.03)$ & Niggemann et al. (1995) \\
\hline & 23 & $0.61 \pm 0.12$ & $(0.31 \pm 0.06)$ & Niggemann et al. (1995) \\
\hline & 24 & $0.13 \pm 0.02$ & $(0.07 \pm 0.01)$ & Niggemann et al. (1995) \\
\hline & 26 & $0.11 \pm 0.01$ & $(0.06 \pm 0.01)$ & Niggemann et al. (1995) \\
\hline & 28 & $0.11 \pm 0.04$ & $(0.06 \pm 0.02)$ & Niggemann et al. (1995) \\
\hline & 34 & $0.76 \pm 0.01$ & $(0.38 \pm 0.01)$ & Niggemann et al. (1995) \\
\hline & 30 & $0.80 \pm 0.08$ & $(0.40 \pm 0.04)$ & Liu and Nagle (2004) \\
\hline \multirow[t]{5}{*}{ Egg PtdCho } & 24 & $2.0 \pm 0.5$ & $(1.0 \pm 0.25)$ & Beblik et al. (1985) \\
\hline & & $1.0-2.0$ & $(0.5-1.0)$ & Schneider et al. (1984a) \\
\hline & & $1.5 \pm 0.5$ & $(0.75 \pm 0.25)$ & Schneider et al. (1984b) \\
\hline & 25 & 0.4 & $(0.2)$ & Sakurai and Kawamura (1983) \\
\hline & & $0.8 \pm 0.2$ & $(0.4 \pm 0.1)$ & Mutz and Helfrich (1990) \\
\hline \multirow[t]{4}{*}{$\mathrm{C}(16: 0) /\left(18: 1 \mathrm{c} \Delta^{9}\right) \mathrm{Ptd}$ Cho } & & $0.25 \pm 0.05$ & $(0.13 \pm 0.03)$ & Kummrow and Helfrich (1991) \\
\hline & 24 & $0.39 \pm 0.09$ & $(0.20 \pm 0.04)$ & Niggemann et al. (1995) \\
\hline & 24 & $0.58 \pm 0.12$ & $(0.29 \pm 0.06)$ & Niggemann et al. (1995) \\
\hline & 30 & 0.85 & $(0.42)$ & Kučerka et al. (2005b) \\
\hline \multirow[t]{4}{*}{$\mathrm{C}(18: 0) /\left(18: 1 \mathrm{c} \Delta^{9}\right) \mathrm{Ptd}$ Cho } & & $1.20 \pm 0.17$ & $(0.60 \pm 0.09)$ & $\begin{array}{l}\text { Song and Waugh (1993) and } \\
\text { Waugh et al. (1992) }\end{array}$ \\
\hline & 14 & $0.6-1.15$ & $(0.3-0.58)$ & Zhelev et al. (1994) \\
\hline & 22 & $0.34 \pm 0.03$ & $(0.17 \pm 0.02)$ & Niggemann et al. (1995) \\
\hline & 22 & $0.32 \pm 0.05$ & $(0.16 \pm 0.03)$ & Niggemann et al. (1995) \\
\hline $\mathrm{C}(18: 0) /\left(18: 1 \mathrm{c} \Delta^{9}\right) \mathrm{PtdCho} /$ cholesterol $(2: 3 \mathrm{~mol} / \mathrm{mol})$ & & $3.3 \pm 0.4$ & $(1.7 \pm 0.2)$ & Song and Waugh (1993) \\
\hline $\operatorname{diC}\left(22: 1 \mathrm{c} \Delta^{13}\right) \operatorname{PtdCho}$ & 30 & 1.27 & $(0.63)$ & Kučerka et al. (2005b) \\
\hline $\operatorname{diC}(12: 0) \operatorname{PtdEtn}$ & 46 & $1.70 \pm 0.26$ & $(0.85 \pm 0.13)$ & Mutz and Helfrich (1990) \\
\hline $\operatorname{diC}(14: 0)$ PtdEtn & 60 & $0.7 \pm 0.1$ & $(0.35 \pm 0.05)$ & Mutz and Helfrich (1990) \\
\hline \multirow[t]{2}{*}{$\mathrm{Gal}_{2} \mathrm{acyl}_{2}$ Gro } & & $0.1 \pm 0.02$ & $(0.05 \pm 0.01)$ & Kummrow and Helfrich (1991) \\
\hline & & $0.12-0.27$ & $(0.06-0.14)$ & Mutz and Helfrich (1990) \\
\hline
\end{tabular}

\footnotetext{
${ }^{a} k_{\mathrm{c}}^{(\mathrm{m})}$ is the mean curvature modulus for a monolayer that is predicted from the experimental bilayer value by using Eq. (16) for uncoupled monolayers.

${ }^{\mathrm{b}} \mathrm{C}(16: 0) /\left(18: 1 \mathrm{c} \Delta^{9}\right)$ PtdCho is 1-palmitoyl-2-oleoyl-sn-glycero-3-phosphocholine, etc.; $\mathrm{Gal}_{2} \mathrm{acyl}_{2}$ Gro is digalactosyl diacylglycerol.
} 
vesicles are also included in Table 3. Recent determinations of $k_{\mathrm{c}}^{(\mathrm{b})}$ that are obtained by the analysis of diffuse $\mathrm{X}$-ray scattering from oriented multibilayer stacks are additionally included in Table 3 . This technique is now emerging as a major source for the bending rigidities of lipid bilayers. The $\mathrm{X}$-ray-derived values that are given in Table 3 (Kučerka et al., 2005a,b; Chu et al., 2005; Liu and Nagle, 2004) originate from a single laboratory and are comparable to those listed in Table 1.

\subsection{Curved monolayer leaflets ( $H_{I I}$-phases)}

Table 4 gives the mean curvature moduli, $k_{\mathrm{c}, \mathrm{p}}^{(\mathrm{m})}$, of lipid monolayers that are determined from phospholipid

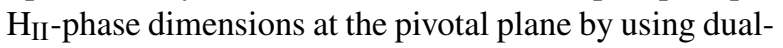
solvent stress. These are a consistent set of data from the same laboratory. Data are reported in units of $k_{\mathrm{B}} T$ in the original publications (where $k_{\mathrm{B}}$ is Boltzmann's constant) and are converted here by using $T=295 \mathrm{~K}\left(22^{\circ} \mathrm{C}\right)$, if the temperature is not stated explicitly. The various measurements of $k_{\mathrm{c}, \mathrm{p}}$ for a lipid monolayer yield a mean value of $(4.5 \pm 0.5) \times 10^{-20} \mathrm{~J}$ for $\operatorname{diC}\left(18: 1 \mathrm{c} \Delta^{9}\right) \operatorname{PtdEtn}$, a value of $4 \times 10^{-20} \mathrm{~J}$ for $\operatorname{diC}\left(18: 1 \mathrm{c} \Delta^{9}\right)$ PtdCho (Chen and Rand, 1997), and a similar value of $4 \times 10^{-20} \mathrm{~J}$ for $30 \mathrm{~mol} \%$ $\operatorname{diC}\left(18: 1 \mathrm{c} \Delta^{9}\right) \operatorname{PtdSer}$ in $\operatorname{diC}\left(18: 1 \mathrm{c} \Delta^{9}\right) \operatorname{PtdEtn}$ (Fuller et al., 2003). Thus, differences in lipid headgroup do not appear to have a large influence on the bending modulus. Table 4 also contains the corresponding values of the spontaneous curvature, $c_{\mathrm{o}, \mathrm{p}}$, for the various lipid monolayers. These values vary greatly with lipid headgroup, as expected on structural grounds (cf. Marsh, 1996b, 1997). All experimental values are referred to the pivotal plane. The corresponding values of bending modulus and spontaneous curvature referred to the neutral plane, $k_{\mathrm{c}, \mathrm{n}}$ and $c_{\mathrm{o}, \mathrm{n}}$, which are calculated by solving the simultaneous equations, Eqs. (29) and (31), numerically, are also included in Table 4. A mean value for the monolayer area extension modulus of $K_{\mathrm{A}}^{(\mathrm{m})}=122 \pm 6 \mathrm{mN} \mathrm{m}^{-1}$, deduced from the bilayer values of Table 1 , was used to calculate these corrections.

The bending rigidities, $k_{\mathrm{c}}^{(\mathrm{b})}$, predicted for a lipid bilayer according to Eq. (16) by using the experimental monolayer values, corrected to the neutral plane, are given in parentheses in Table 4. It is seen from comparison with Table 1 that the bilayer values are generally consistent with the direct determinations by pipette aspiration on giant lipid vesicles, particularly in the case of $\operatorname{diC}\left(18: 1 \mathrm{c} \Delta^{9}\right)$ PtdCho for which there are measurements in common. This result is of considerable significance because it implies that the formalism for small elastic deformations can be applied to situations of high curvature, as in $\mathrm{H}_{\mathrm{II}}$-phases. The condition for this is that the monolayer curvatures be referred to the pivotal plane (rather than to the outer surface), the position of which in relation to the lipid surface changes with varying water content of the $\mathrm{H}_{\mathrm{II}}$-phases (Leikin et al., 1996; Rand et al., 1990).

One situation in which the monolayer values of bend-

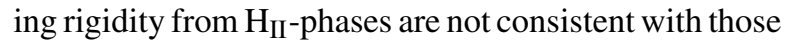
derived from bilayers is for admixtures with cholesterol. Whereas addition of cholesterol changes the monolayer values of $k_{\mathrm{c}}^{(\mathrm{m})}$ in Table 4 relatively little, cholesterol strongly increases the bending rigidity, $k_{\mathrm{c}}^{(\mathrm{b})}$, of lipid bilayers (see Tables 1-3), and concomitantly also the area extension moduli, $K_{\mathrm{A}}^{(\mathrm{b})}$ (Evans and Rawicz, 1990; Needham and Nunn, 1990). Based on comparison of Eqs. (18) and (19), or of Eqs. (20) and (21), a possible explanation for this difference is that cholesterol in bilayers induces a strong coupling of the monolayer leaflets, in addition to increasing the intrinsic area extension modulus, $K_{\mathrm{A}}^{(\mathrm{b})}$.

\subsection{Gaussian curvature}

Table 5 gives experimental estimates of the ratio, $\bar{k}_{\mathrm{c}} / k_{\mathrm{c}}$, of the Gaussian curvature modulus to the mean curvature modulus, for three different fluid phospholipid systems. The first value, for a monolayer, is based on the swelling behaviour of inverse cubic phases formed from a mixture of mono-oleoyl glycerol, dioleoyl phosphatidylcholine and dioleoyl phosphatidylethanolamine (Templer et al., 1998). This lipid mixture forms highly swollen inverse bicontinuous cubic phases; it was argued that previous estimates of this type were restricted to systems in which the curvature was higher, the harmonic elastic approximation questionable, and interbilayer forces could not be neglected (Templer et al., 1995). The ratio of mean to Gaussian bending rigidities for bilayers that is predicted for this system by using Eq. (17) is very small. The second value is an estimate for $N$ methyl dioleoyl phosphatidylethanolamine at the lamellar to cubic $\left(\mathrm{L}_{\alpha} / \mathrm{Q}_{\mathrm{II}}\right)$ phase transition $\left(T_{\mathrm{Q}} \approx 55^{\circ} \mathrm{C}\right)$. At the transition temperature, the ratio of curvature moduli for the bilayer is identically zero, and that for an individual monolayer is given by: $\left(\bar{k}_{\mathrm{c}}^{(\mathrm{m})} / k_{\mathrm{c}}^{(\mathrm{m})}\right)_{T_{\mathrm{Q}}}=2 \delta c_{\mathrm{o}}^{(\mathrm{m})}\left(T_{\mathrm{Q}}\right)$ (Siegel and Kozlov, 2004). The third experimental estimate in Table 5 is an apparent value deduced from the shape of mechanically pierced giant vesicles of egg lecithin (Lorenzen et al., 1986). This is an apparent value for bilayers. All three experimental estimates produce a consistent mean value of $\bar{k}_{\mathrm{c}} / k_{\mathrm{c}}=-(0.80 \pm 0.05)$. For the stability of $\mathrm{L}_{\alpha}$ and $\mathrm{Q}_{\text {II }}$ phases, it has been argued that this ratio must lie within the range $-1<\bar{k}_{\mathrm{c}}^{(\mathrm{m})} / k_{\mathrm{c}}^{(\mathrm{m})}<0$ 
Table 4

Elastic bending constants (and spontaneous curvatures) for lipid monolayers from dual-solvent stress experiments on lipid $\mathrm{H}_{\mathrm{II}}$-phases. Original experimental values, $k_{\mathrm{c}, \mathrm{p}}^{(\mathrm{m})}\left(\right.$ and $c_{\mathrm{o}, \mathrm{p}}$ ), are referred to the pivotal plane ${ }^{\mathrm{a}}$

\begin{tabular}{|c|c|c|c|c|c|c|c|}
\hline Lipid $^{b}$ & $T\left({ }^{\circ} \mathrm{C}\right)$ & $k_{\mathrm{c}, \mathrm{p}}^{(\mathrm{m})}\left(\times 10^{-19} \mathrm{~J}\right)$ & $c_{\mathrm{o}, \mathrm{p}}\left(\mathrm{nm}^{-1}\right)$ & $k_{\mathrm{c}, \mathrm{n}}^{(\mathrm{m})}\left(\times 10^{-19} \mathrm{~J}\right)$ & $c_{\mathrm{o}, \mathrm{n}}\left(\mathrm{nm}^{-1}\right)$ & $k_{\mathrm{c}}^{(\mathrm{b})}\left(\times 10^{-19} \mathrm{~J}\right)$ & Reference \\
\hline \multirow[t]{2}{*}{$\operatorname{diC}\left(18: 1 c \Delta^{9}\right) \operatorname{PtdEtn}$} & \multirow[t]{2}{*}{22} & $0.47 \pm 0.02$ & $-0.351 \pm 0.018$ & $(0.39 \pm 0.02)$ & $-(0.367 \pm 0.018)$ & $(0.94 \pm 0.04)$ & Chen and Rand (1997) \\
\hline & & $0.49 \pm 0.02$ & $-0.353 \pm 0.004$ & $(0.41 \pm 0.02)$ & $-(0.370 \pm 0.004)$ & $(0.98 \pm 0.04)$ & Chen and Rand (1998) \\
\hline $\begin{array}{l}\operatorname{diC}\left(18: 1 \mathrm{c} \Delta^{9}\right) \operatorname{PtdEtn} / \text { cholesterol } \\
\quad(7: 3 \mathrm{~mol} / \mathrm{mol})\end{array}$ & 22 & $0.52 \pm 0.02$ & $-0.439 \pm 0.038$ & $(0.39 \pm 0.02)$ & $-(0.472 \pm 0.038)$ & $(1.04 \pm 0.04)$ & Chen and Rand (1997) \\
\hline \multirow[t]{6}{*}{$\operatorname{diC}\left(18: 1 \mathrm{c} \Delta^{9}\right) \operatorname{PtdEtn} / 16 \mathrm{wt} . \%$ tetradecane } & 22 & $0.55 \pm 0.02$ & $-0.340 \pm 0.023$ & $(0.45 \pm 0.02)$ & $-(0.357 \pm 0.023)$ & $(1.09 \pm 0.04)$ & Chen and Rand (1997) \\
\hline & & $0.49 \pm 0.02$ & $-0.348 \pm 0.004$ & $(0.41 \pm 0.02)$ & $-(0.364 \pm 0.004)$ & $(0.98 \pm 0.05)$ & Chen and Rand (1998) \\
\hline & 22 & $0.44 \pm 0.05$ & $-0.342 \pm 0.004$ & $(0.38 \pm 0.05)$ & $-(0.356 \pm 0.004)$ & $(0.88 \pm 0.10)$ & Fuller and Rand (2001) \\
\hline & 20 & 0.45 & -0.359 & $(0.38)$ & $-(0.375)$ & $(0.90)$ & Fuller et al. (2003) \\
\hline & 25 & $0.45 \pm 0.02$ & -0.352 & $(0.38 \pm 0.02)$ & $-(0.367)$ & $(0.90 \pm 0.04)$ & Leikin et al. (1996) \\
\hline & 22 & 0.85 & -0.324 & $(0.66)$ & $-(0.346)$ & (1.7) & Rand et al. (1990) \\
\hline $\begin{array}{l}\operatorname{diC}\left(18: 1 \mathrm{c} \Delta^{9}\right) \operatorname{PtdEtn} / \mathrm{cholesterol} \\
\quad(7: 3 \mathrm{~mol} / \mathrm{mol}) / 16 \mathrm{wt} . \% \text { tetradecane }\end{array}$ & 22 & $0.63 \pm 0.02$ & $-0.370 \pm 0.018$ & $(0.49 \pm 0.02)$ & $-(0.394 \pm 0.018)$ & $(1.25 \pm 0.04)$ & Chen and Rand (1997) \\
\hline $\begin{array}{l}\operatorname{diC}\left(18: 1 \mathrm{c} \Delta^{9}\right) \operatorname{PtdEtn} / \operatorname{diC}\left(18: 1 \mathrm{c} \Delta^{9}\right) \operatorname{PtdSer} \\
\quad(7: 3 \mathrm{~mol} / \mathrm{mol}) / 16 \text { wt. } \% \text { tetradecane }\end{array}$ & 20 & 0.38 & -0.227 & $(0.36)$ & $-(0.231)$ & $(0.77)$ & Fuller et al. (2003) \\
\hline $\begin{array}{l}\operatorname{diC}\left(18: 1 \mathrm{c} \Delta^{9}\right) \operatorname{PtdEtn} / \operatorname{diC}\left(18: 1 \mathrm{c} \Delta^{9}\right) \text { Gro } \\
\quad(2: 1 \mathrm{~mol} / \mathrm{mol}) / 16 \mathrm{wt} . \% \text { tetradecane }\end{array}$ & 25 & $0.56 \pm 0.02$ & -0.517 & $(0.37 \pm 0.02)$ & $-(0.572)$ & $(1.12 \pm 0.04)$ & Leikin et al. (1996) \\
\hline $\begin{array}{l}\operatorname{diC}\left(18: 1 \mathrm{c} \Delta^{9}\right) \operatorname{PtdEtn} / \mathrm{C}(12: 0) \text { lysoPtdEtn } \\
(15 \mathrm{~mol} \%) / 16 \text { wt. } \% \text { tetradecane }\end{array}$ & 22 & $0.40 \pm 0.05$ & $-0.291 \pm 0.004$ & $(0.36 \pm 0.05)$ & $-(0.299 \pm 0.004)$ & $(0.79 \pm 0.10)$ & Fuller and Rand (2001) \\
\hline $\begin{array}{l}\operatorname{diC}\left(18: 1 \mathrm{c} \Delta^{9}\right) \operatorname{PtdEtn} / \mathrm{C}(18: 0) \text { lysoPtdEtn } \\
\quad(14 \mathrm{~mol} \%) / 16 \text { wt. } \% \text { tetradecane }\end{array}$ & 22 & $0.35 \pm 0.05$ & $-0.309 \pm 0.004$ & $(0.32 \pm 0.05)$ & $-(0.317 \pm 0.004)$ & $(0.69 \pm 0.10)$ & Fuller and Rand (2001) \\
\hline $\begin{array}{l}\operatorname{diC}\left(18: 1 \mathrm{c} \Delta^{9}\right) \operatorname{PtdEtn} / \mathrm{C}\left(18: 1 \mathrm{c} \Delta^{9}\right) \text { lysoPtdEtn } \\
\quad(15 \mathrm{~mol} \%) / 16 \mathrm{wt} \% \text { tetradecane }\end{array}$ & 22 & $0.44 \pm 0.05$ & $-0.305 \pm 0.004$ & $(0.39 \pm 0.05)$ & $-(0.315 \pm 0.004)$ & $(0.87 \pm 0.10)$ & Fuller and Rand (2001) \\
\hline $\begin{array}{l}\operatorname{diC}\left(18: 1 \mathrm{c} \Delta^{9}\right) \operatorname{PtdEtn} / \mathrm{C}(12: 0) \text { lysoPtdCho } \\
\quad(12 \mathrm{~mol} \%) / 16 \text { wt. } \% \text { tetradecane }\end{array}$ & 22 & $0.48 \pm 0.05$ & $-0.282 \pm 0.004$ & $(0.43 \pm 0.05)$ & $-(0.290 \pm 0.004)$ & $(0.96 \pm 0.10)$ & Fuller and Rand (2001) \\
\hline $\begin{array}{l}\operatorname{diC}\left(18: 1 \mathrm{c} \Delta^{9}\right) \operatorname{PtdEtn} / \mathrm{C}\left(18: 1 \mathrm{c} \Delta^{9}\right) \text { lysoPtdCho } \\
\quad(10 \mathrm{~mol} \%) / 16 \text { wt. } \% \text { tetradecane }\end{array}$ & 22 & $0.46 \pm 0.05$ & $-0.287 \pm 0.004$ & $(0.41 \pm 0.05)$ & $-(0.296 \pm 0.004)$ & $(0.93 \pm 0.10)$ & Fuller and Rand (2001) \\
\hline $\operatorname{diC}\left(18: 1 \mathrm{c} \Delta^{9}\right) \mathrm{PtdCho} / 16 \mathrm{wt} . \%$ tetradecane & 32 & $0.38 \pm 0.02$ & $-0.115 \pm 0.005$ & $(0.37 \pm 0.02)$ & $-(0.115 \pm 0.005)$ & $(0.76 \pm 0.04)$ & Chen and Rand (1997) \\
\hline $\begin{array}{l}\operatorname{diC}\left(18: 1 \mathrm{c} \Delta^{9}\right) \operatorname{PtdCho} / \text { cholesterol } \\
\quad(1: 1 \mathrm{~mol} / \mathrm{mol}) / 16 \mathrm{wt} . \% \text { tetradecane }\end{array}$ & 32 & $0.47 \pm 0.02$ & $0.244 \pm 0.012$ & $(0.43 \pm 0.02)$ & $-(0.249 \pm 0.012)$ & $(0.93 \pm 0.05)$ & Chen and Rand (1997) \\
\hline
\end{tabular}

${ }^{a}$ Values referred to the neutral plane, $k_{\mathrm{c}, \mathrm{n}}^{(\mathrm{m})}$ and $c_{\mathrm{o}, \mathrm{n}}$, are calculated from the experimental values by using Eqs. (29) and (31) with $K_{\mathrm{A}}^{(\mathrm{m})}=122 \pm 6 \mathrm{mN} \mathrm{m}^{-1}$. $k_{\mathrm{c}}^{(\mathrm{b})}$ is the mean curvature modulus for a bilayer that is predicted from the corrected monolayer value, $k_{\mathrm{c}, \mathrm{n}}^{(\mathrm{m})}$, by using Eq. (16) for uncoupled monolayers.

${ }^{b} \mathrm{C}(12: 0)$ lysoPtdEtn is 1-lauroyl-2-lyso-sn-glycero-3-phosphoethanolamine, etc. 
Table 5

Gaussian bending moduli for lipid (monolayers) ${ }^{\mathrm{a}}$

\begin{tabular}{|c|c|c|c|c|c|c|}
\hline Lipid $^{\text {b }}$ & $T\left({ }^{\circ} \mathrm{C}\right)$ & $\bar{k}_{\mathrm{c}}^{(\mathrm{m})} / k_{\mathrm{c}}^{(\mathrm{m})}$ & $k_{\mathrm{c}}^{(\mathrm{m})}\left(\times 10^{-19} \mathrm{~J}\right)$ & $\bar{k}_{\mathrm{c}}^{(\mathrm{m})}\left(\times 10^{-19} \mathrm{~J}\right)$ & $\bar{k}_{\mathrm{c}}^{(\mathrm{b})} / k_{\mathrm{c}}^{(\mathrm{b}) \mathrm{c}}$ & Reference \\
\hline $\begin{array}{l}\mathrm{C}\left(18: 1 \mathrm{c} \Delta^{9}\right) \mathrm{Gro} / \operatorname{diC}\left(18: 1 \mathrm{c} \Delta^{9}\right) \\
\operatorname{PtdCho} / \operatorname{diC}\left(18: 1 \mathrm{c} \Delta^{9}\right) \operatorname{PtdEtn} \\
\text { 58:38:4 } \mathrm{mol} / \mathrm{mol}\end{array}$ & 25 & $-0.75 \pm 0.08$ & $(0.41)$ & $(-0.31 \pm 0.03)$ & $\approx 0.01$ & Templer et al. (1998) \\
\hline $\operatorname{diC}\left(18: 1 \mathrm{c} \Delta^{9}\right) \operatorname{PtdEtn}-\mathrm{Me}$ & 55 & $-0.83 \pm 0.08$ & $(0.45)$ & $(-0.38 \pm 0.04)$ & $0^{\mathrm{d}}$ & Siegel and Kozlov (2004) \\
\hline Egg PtdCho + 30\% PtdEtn & R.T. & $-0.83 \pm 0.12^{\mathrm{e}}$ & & & & Lorenzen et al. (1986) \\
\hline
\end{tabular}

${ }^{a}$ The quantity determined experimentally is $\bar{k}_{\mathrm{c}}^{(\mathrm{m})} / k_{\mathrm{c}}^{(\mathrm{m})}$. Values for $\bar{k}_{\mathrm{c}}^{(\mathrm{m})}$ are deduced by using the values of $k_{\mathrm{c}}^{(\mathrm{m})}$ that are indicated in parentheses.

${ }^{\mathrm{b}} \mathrm{C}\left(18: 1 \mathrm{c} \Delta^{9}\right)$ Gro is monooleoyl glycerol; PtdEtn-Me is $N$-methyl phosphatidylethanolamine.

${ }^{\mathrm{c}}$ Values for $\bar{k}_{\mathrm{c}}^{(\mathrm{b})} / k_{\mathrm{c}}^{(\mathrm{b})}$ are deduced from Eq. (17), with $k_{\mathrm{c}}^{(\mathrm{b})}=2 k_{\mathrm{c}}^{(\mathrm{m})}$.

d $\bar{k}_{\mathrm{c}}^{(\mathrm{b})} / k_{\mathrm{c}}^{(\mathrm{b})}=0$, by definition, at the lamellar-cubic phase transition $\left(T=T_{\mathrm{Q}}\right)$.

e Apparent experimental value for a bilayer, not a monolayer (see Lorenzen et al., 1986).

(Templer et al., 1998). Values of the monolayer Gaussian curvature modulus that are deduced from the mean curvature modulus together with the values of the ratio $\bar{k}_{\mathrm{c}} / k_{\mathrm{c}}$ are given in parentheses in Table 5.

\section{Conclusions}

Although there are relatively few measurements in common, determinations of the mean curvature modulus for lipid bilayers by pipette aspiration appear to be consistently smaller than those determined from analysis of shape fluctuations on giant vesicles and other methods. Measurements of the mean curvature modulus for lipid monolayer leaflets in $\mathrm{H}_{\mathrm{II}}$-phases are reasonably consistent with bilayer measurements by pipette aspiration, if the bilayer leaflets are assumed to be uncoupled. On the whole, $k_{\mathrm{c}}^{(\mathrm{m})} \approx 10 k_{\mathrm{B}} T$ for monolayers, and twice this, or more, for bilayers. The only well-established effect of the structure of the lipid molecules on the mean curvature modulus is the quadratic dependence on acyl chain length, but this does not extend to polyunsaturated lipids. An unambiguous comparison of the effects of lipid headgroup on the mean curvature modulus is currently available only from studies on $\mathrm{H}_{\mathrm{II}}$-phases. These suggest that the influence of the polar group is not very large for phospholipids. Cholesterol, however, does have a very pronounced effect on the mean curvature modulus of bilayers. At the present, quantitative information on the Gaussian curvature modulus is rather sparse, but suggests that $\bar{k}_{\mathrm{c}} \approx-0.8 k_{\mathrm{c}}$ for lipid monolayers.

\section{References}

Attard, G.S., Templer, R.H., Smith, W.S., Hunt, A.N., Jackowski, S., 2000. Modulation of CTP:phosphocholine cytidylyltransferase by membrane curvature elastic stress. Proc. Natl. Acad. Sci. U.S.A. 97, 9032-9036.

Beblik, G., Servuss, R.M., Helfrich, W., 1985. Bilayer bending rigidity of some synthetic lecithins. J. Phys. France 46, 1773-1778.
Bivas, I., Hanusse, P., Bothorel, P., Lalanne, J., Aguerre-Chariol, O., 1987. An application of the optical microscopy to the determination of the curvature elastic modulus of biological and model membranes. J. Phys. France 48, 855-867.

Bloom, M., Evans, E., Mouritsen, O.G., 1991. Physical properties of the fluid lipid-bilayer component of cell membranes: a perspective. Quart. Rev. Biophys. 24, 293-397.

Cevc, G., Marsh, D., 1987. Phospholipid Bilayers. Physical Principles and Models. Wiley-Interscience, New York.

Chen, Z., Rand, R.P., 1997. The influence of cholesterol on phospholipid membrane curvature and bending elasticity. Biophys. J. 73, 267-276.

Chen, Z., Rand, R.P., 1998. Comparative study of the effects of several $n$-alkanes on phospholipid hexagonal phases. Biophys. J. 74, 944-952.

Chernomordik, L.V., Kozlov, M.M., 2003. Protein-lipid interplay in fusion and fission of biological membranes: tipping the balance of membrane stability. Annu. Rev. Biochem. 72, 175-207.

Chu, N., Kučerka, N., Liu, Y., Tristram-Nagle, S., Nagle, J.F., 2005. Anomalous swelling of lipid bilayer stacks is caused by softening of the bilayer modulus. Phys. Rev. E 71, 041904-1-041904-8.

Deuling, H.J., Helfrich, W., 1976. The curvature elasticity of fluid membranes: a catalogue of vesicle shapes. J. Phys. France 37, $1335-1345$.

Duwe, H.P., Engelhardt, H., Zilker, A., Sackmann, E., 1987. Curvature elasticity of smectic A lipid bilayers and cell plasma membranes. Mol. Cryst. Liq. Cryst. 152, 1-7.

Duwe, H.P., Kaes, J., Sackmann, E., 1990. Bending elastic moduli of lipid bilayers: modulation by solutes. J. Phys. France 51, 945-962.

Engelhardt, H., Duwe, H.P., Sackmann, E., 1985. Bilayer bending elasticity measured by Fourier analysis of thermally excited surface undulations of flaccid vesicles. J. Phys. Lett. 46, L395-L400.

Evans, E.A., Kwok, R., 1982. Mechanical calorimetry of large dimyristoylphosphatidylcholine vesicles in the phase transition region. Biochemistry 21, 4874-4879.

Evans, E.A., Parsegian, V.A., 1986. Thermal-mechanical fluctuations enhance repulsion between bimolecular layers. Proc. Natl. Acad. Sci. U.S.A. 83, 7132-7136.

Evans, E.A., Rawicz, W., 1990. Entropy-driven tension and bending elasticity in condensed-fluid membranes. Phys. Rev. Lett. 64, 2094-2097.

Evans, E.A., Skalak, R., 1980. Mechanics and Thermodynamics of Biomembranes. CRC Press, Boca Raton, FL.

Faucon, J.F., Mitov, M.D., Méléard, P., Bivas, I., Bothorel, P., 1989. Bending elasticity and thermal fluctuations of lipid membranes. 
Theoretical and experimental requirements. J. Phys. France 50, 2389-2414.

Fernandez-Puente, L., Bivas, I., Mitov, M.D., Méléard, P., 1994. Temperature and chain-length effects on bending elasticity of phosphatidylcholine bilayers. Europhys. Lett. 28, 181-186.

Fuller, N., Benatti, C.R., Rand, R.P., 2003. Curvature and bending constants for phosphatidylserine-containing membranes. Biophys. J. 85, 1667-1674.

Fuller, N., Rand, R.P., 2001. The influence of lysolipids on the spontaneous curvature and bending elasticity of phospholipid membranes. Biophys. J. 81, 243-254.

Gruner, S.L., 1985. Intrinsic curvature hypothesis for biomembrane lipid composition: a role for non-bilayer lipids. Proc. Natl. Acad. Sci. U.S.A. 82, 3665-3669.

Gruner, S.M., Parsegian, V.A., Rand, R.P., 1986. Directly measured deformation energy of phospholipid $\mathrm{H}_{\mathrm{II}}$ hexagonal phases. Faraday Discuss. Chem. Soc. 81, 29-37.

Helfrich, W., 1973. Elastic properties of lipid bilayers: theory and possible experiments. Z. Naturforsch. 28c, 693-703.

Helfrich, W., 1974. Blocked lipid exchange in bilayers and its possible influence on the shape of vesicles. Z. Naturforsch. 29c, 510 515.

Helfrich, W., 1978. Steric interaction of fluid membranes in multilayer systems. Z. Naturforsch. 33a, 305-315.

Helfrich, W., 1981. Amphiphilic mesophases made of defects. In: Balian, R., Kléman, M., Poirier, J.P. (Eds.), Les Houches, Session XXXV, 1980, Physics of Defects. North-Holland Publishing Company, Amsterdam, pp. 716-755.

Helfrich, W., Kozlov, M.M., 1993. Bending tensions and the bending rigidity of fluid membranes. J. Phys. II France 3, 287-292.

Hønger, T., Mortensen, K., Ipsen, J.H., Lemmich, J., Bauer, R., Mouritsen, O.G., 1994. Anomalous swelling of multilamellar lipid bilayers in the transition region by renormalization of curvature elasticity. Phys. Rev. Lett. 72, 3911-3914.

Keller, S.L., Bezrukov, S.M., Gruner, S.M., Tate, M.W., Vodyanoy, I., Parsegian, V.A., 1993. Probability of alamethicin conductance states varies with nonlamellar tendency of bilayer phospholipids. Biophys. J. 65, 23-27.

Kozlov, M.M., Winterhalter, M., 1991. Elastic moduli and neutral surface for strongly curved monolayers. Analysis of experimental results. J. Phys. II France 1, 1085-1100.

Kučerka, N., Liu, Y., Chu, N., Petrache, H.I., Tristram-Nagle, S., Nagle, J.F., 2005a. Structure of fully hydrated fluid phase DMPC and DLPC lipid bilayers using X-ray scattering from oriented multilamellar arrays and from unilamellar vesicles. Biophys. J. 88, 2626-2637.

Kučerka, N., Tristram-Nagle, S., Nagle, J.F., 2005b. Structure of fully hydrated fluid phase lipid bilayers with monounsaturated chains. J. Membr. Biol. 208, 193-202.

Kummrow, M., Helfrich, W., 1991. Deformation of giant lipid vesicles by electric fields. Phys. Rev. A 44, 8356-8360.

Leikin, S., Kozlov, M.M., Fuller, N.L., Rand, R.P., 1996. Measured effects of diacylglycerol on structural and elastic properties of phospholipid membranes. Biophys. J. 71, 2623-2632.

Lipowsky, R., 1991. The conformation of membranes. Nature 349, 475-481.

Liu, Y., Nagle, J.F., 2004. Diffuse scattering provides material parameters and electron density profiles of biomembranes. Phys. Rev. E 69, 040901-1-040901-4.

Lorenzen, S., Servuss, R.M., Helfrich, W., 1986. Elastic torques about membrane edges - a study of pierced egg lecithin vesicles. Biophys. J. 50, 565-572.
Marsh, D., 1990. Handbook of Lipid Bilayers. CRC Press, Boca Raton, FL.

Marsh, D., 1996a. Lateral pressure in membranes. Biochim. Biophys. Acta 1286, 183-223.

Marsh, D., 1996b. Intrinsic curvature in normal and inverted lipid structures and in membranes. Biophys. J. 70, 2248-2255.

Marsh, D., 1997. Nonlamellar packing parameters for diacylglycerols. Biophys. J. 72, 2834-2836.

Marsh, D., Shanmugavadivu, B., Kleinschmidt, J.H., 2006. Membrane elastic fluctuations and the insertion and tilt of $\beta$-barrel proteins. Biophys. J. 91, 227-232.

McIntosh, T.J., Advani, S., Burton, R.E., Zhelev, D.V., Needham, D., Simon, S.A., 1995. Experimental tests for protrusion and undulation pressures in phospholipid bilayers. Biochemistry 34 , $8520-8532$.

Méléard, P., Gerbeaud, C., Pott, T., Fernandez-Puente, L., Bivas, I., Mitov, M.D., Dufourcq, J., Bothorel, P., 1997. Bending elasticities of model membranes: influences of temperature and sterol content. Biophys. J. 72, 2616-2629.

Mishima, K., Nakamae, S., Ohshima, H., Kondo, T., 2001. Curvature elasticity of multilamellar lipid bilayers close to the chain-melting transition. Chem. Phys. Lipids 110, 27-33.

Mutz, M., Helfrich, W., 1990. Bending rigidities of some biological model membranes as obtained from the Fourier analysis of contour sections. J. Phys. France 51, 991-1002.

Needham, D., Nunn, R.S., 1990. Elastic deformation and failure of lipid bilayer membranes containing cholesterol. Biophys. J. 58, 997-1000.

Niggemann, G., Kummrow, M., Helfrich, W., 1995. The bending rigidity of phosphatidylcholine bilayers: dependences on experimental method, sample cell sealing and temperature. J. Phys. II France 5, 413-425.

Perozo, E., Kloda, A., Cortes, D.M., Martinac, B., 2002. Physical principles underlying the transduction of bilayer deformation forces during mechanosensitive channel gating. Nat. Struct. Biol. 9, 696-703.

Petrov, A.G., Bivas, I., 1984. Elastic and flexoelectric aspects of outof-plane fluctuations in biological and model membranes. Prog. Surf. Sci. 16, 389-512.

Rand, R.P., Fuller, N.L., Gruner, S., Parsegian, V.A., 1990. Membrane curvature, lipid segregation, and structural transitions for phospholipids under dual-solvent stress. Biochemistry 29, 76-87.

Rawicz, W., Olbrich, K.C., McIntosh, T., Needham, D., Evans, E., 2000. Effect of chain length and unsaturation on elasticity of lipid bilayers. Biophys. J. 79, 328-339.

Sakurai, I., Kawamura, Y., 1983. Magnetic field-induced orientation and bending of the myelin figures of phosphatidylcholine. Biochim. Biophys. Acta 735, 189-192.

Schneider, M.B., Jenkins, J.T., Webb, W.W., 1984a. Thermal fluctuations of large cylindrical phospholipid vesicles. Biophys. J. 45, 891-899.

Schneider, M.B., Jenkins, J.T., Webb, W.W., 1984b. Thermal fluctuations of large quasispherical bimolecular phospholipid vesicles. J. Phys. France 45, 1457-1472.

Seddon, J.M., 1990. Structure of the inverted hexagonal $\left(\mathrm{H}_{\mathrm{II}}\right)$ phase, and non-lamellar phase transitions of lipids. Biochim. Biophys. Acta 1031, 1-69.

Siegel, D.P., 1999. The modified stalk mechanism of lamellar/inverted phase transitions and its implications for membrane fusion. Biophys. J. 76, 291-313.

Siegel, D.P., Kozlov, M.M., 2004. The Gaussian curvature elastic modulus of $\mathrm{N}$-monomethylated dioleoylphosphatidylethanolamine: 
relevance to membrane fusion and lipid phase behavior. Biophys. J. 87, 366-374.

Song, J.B., Waugh, R.E., 1993. Bending rigidity of SOPC membranes containing cholesterol. Biophys. J. 64, 1967-1970.

Southwell, R.V., 1941. An Introduction to the Theory of elasticity. Oxford University Press, London.

Szleifer, I., Kramer, D., Ben-Shaul, A., Gelbart, W.M., Safran, S.A., 1990. Molecular theory of curvature elasticity in surfactant films. J. Chem. Phys. 92, 6800-6817.

Templer, R.H., Khoo, B.J., Seddon, J.M., 1998. Gaussian curvature modulus of an amphiphilic monolayer. Langmuir 14, 7427-7434.
Templer, R.H., Turner, D.C., Harper, P., Seddon, J.M., 1995. Corrections to some models of the curvature elastic energy of inverse bicontinuous cubic phases. J. Phys. II France 5, 1053-1065.

Vitkova, V., Méléard, P., Pott, T., Bivas, I., 2006. Alamethicin influence on the membrane bending elasticity. Eur. Biophys. J. 35, 281-286.

Waugh, R.E., Song, J., Svetina, S., Zeks, B., 1992. Local and nonlocal curvature elasticity in bilayer membranes by tether formation from lecithin vesicles. Biophys. J. 61, 974-982.

Zhelev, D.V., Needham, D., Hochmuth, R.M., 1994. A novel micropipet method for measuring the bending modulus of vesicle membranes. Biophys. J. 67, 720-727. 